\title{
Review of Chinese Social Media Platforms Focusing on WeChat and Weibo: Digital curating and cultural promotions
}

\author{
Han Bao \\ King's College London \\ The Strand, London WC2R 2LS, UK \\ han.bao@kcl.ac.uk
}

\begin{abstract}
The growing scope of technological development and the extent of the specific application of new media in the museum sector are now intrinsic to their promotion, application and operation. Social media, with its large and diverse user group demographics, is an ideal place to disseminate exhibition collections and knowledge worldwide. Many museums now utilise social media by registering on Facebook, Twitter and YouTube to share information, interact with visitors and share educational content. Museums further promote their collections by applying shared Creative Commons licensing to images of exhibitions and objects in their collections on websites like Flickr and Pinterest. In China, WeChat and Sina Weibo are the largest social media platforms. This paper will first introduce the current developmental state of digital curation and social media in China. It will analyse Weibo, how art and culture are administered in China as a state function, and how social media is involved. It will then use a case study on the use of exhibitions as part of a WeChat blog strategy. Finally, this paper will seek to propose how soft power and cultural diplomacy can extend within China in the digital age.
\end{abstract}

WeChat. Weibo. Perseveration. Interaction. Soft power.

\section{INTRODUCTION}

\subsection{Background of Interaction in Art}

In East Asia, people are obsessed with taking photos and letting others know where they are. It is not uncommon to see people walking through galleries only to take a picture of each work of art without stopping and looking at the piece itself, and then posting the images immediately on their social media pages. This is an example of why many decry social media for its general contribution to a 'dumbing down' of culture. Contrary to this, many in the art world, such as artists and gallery owners, focus on the positives of social media. They are adamant that rather than killing art, social media is democratising it.

Although the people taking pictures of artworks in galleries without looking at them may seem misguided, social media has never supposed to have been a replacement for seeing art 'in the flesh'. It is actually a valuable way of engaging and exchanging with new audiences. Individuals may live in a "digital bubble", close to others physically, but far away from them in their digital world (Bowen, \& Giannini 2014). Taking a photo of a Picasso painting at the Tate Modern for example and uploading it to friends is disseminating an image in a way that is faster and greater than anything Walter Benjamin imagined possible in his essay in 1935, The Work of Art in the Age of Mechanical Reproduction. However, I would argue that the question of whether the 'aura' discussed by Benjamin (1935), which means the magical essence of the original, which is still an important issue in the digital age?

The aura includes the sensory experience of the distance between the viewer and the work of art. The aura has therefore somewhat disappeared in the modern age because art has become reproducible. However, our desire to take images of the original suggests that this aura is still there in some form. This remains a part of human's belief in capturing authenticity. We have a brief partial ownership of the aura of an artwork by standing in front of it or simply by taking its picture. We then feel that we have 'seen it', which is a form of virtual ownership created by seeing the original and its 'aura'. This is an 
improvement on seeing digital reproductions that do not have these auras and people travel across the world to galleries and museums to have these experiences.

It is also worth noting that social media has many different uses for different people: galleries use it as a marketing tool; art lovers use it to post art pictures, discuss works and as a form of bragging rights; critics use it to enlighten and pontificate; and artists take the opportunity to share their creative vision.

While galleries and exhibitions are more popular than ever, what other examples of interaction between social media and visual arts are there? Places such as the Unit in London (theunitldn.com) often focus on Instagram shows. Developed by Burt and Kennedy, who take social media very seriously, their show, Paint Guide, in 2016, was 'the first Instagram-curated art exhibition' available online (uk.businessinsider.com/instagram-gallery-unitlondon-1-2015). If art is led by social media, there is a question relating to the risk that artworks will be created to fit formats favourable to social media and calculated to meet a market algorithm. This debate is ongoing and will continue as the digital world expands.

\subsection{Context of Chinese Social Media Platforms and Museum Function}

According to Joseph V. Noble (1920-2007), the Vice Director of Administration at the Metropolitan
Museum of Art, New York, museums have five functions: collection, preservation, research, interpretation and exhibition (Hertz 1993). The Dutch museum curator P. V. Munsch summarised his functions as collection, custody, research and education. However, dissemination is just the initial foundation.

If the "post museum" is defined by "a shift from the institution as the custodian of knowledge, which it bestows on a grateful citizenry, to the institution as a site at which visitors share their knowledge' (Eilean 2007). What do we do about the fact that visitors to the museum are in the minority and from a narrow section of the population? According to Gibson (2012), it is important understanding everyday participation- articulating cultural value, which includes public perceptions of museums and culture, mapping participation and every day and facilitated participation.

With the development of new media, smartphones have promoted a consumption model that features resource sharing, intelligent devices and diversified scenarios. According to CNNIC (2017), as of December 2016, the number of mobile Internet users in China had reached 695 million, representing an increase of 75.5 million since the end of 2015. Mobile online netizens accounted for $95.1 \%$ of the total netizen population in China, while this percentage was $90.1 \%$ in 2015 in Figure 1 (CNNIC 2017). The proportion of mobile netizens further climbed higher.

\section{CNIC 中国互联网络售息中心}

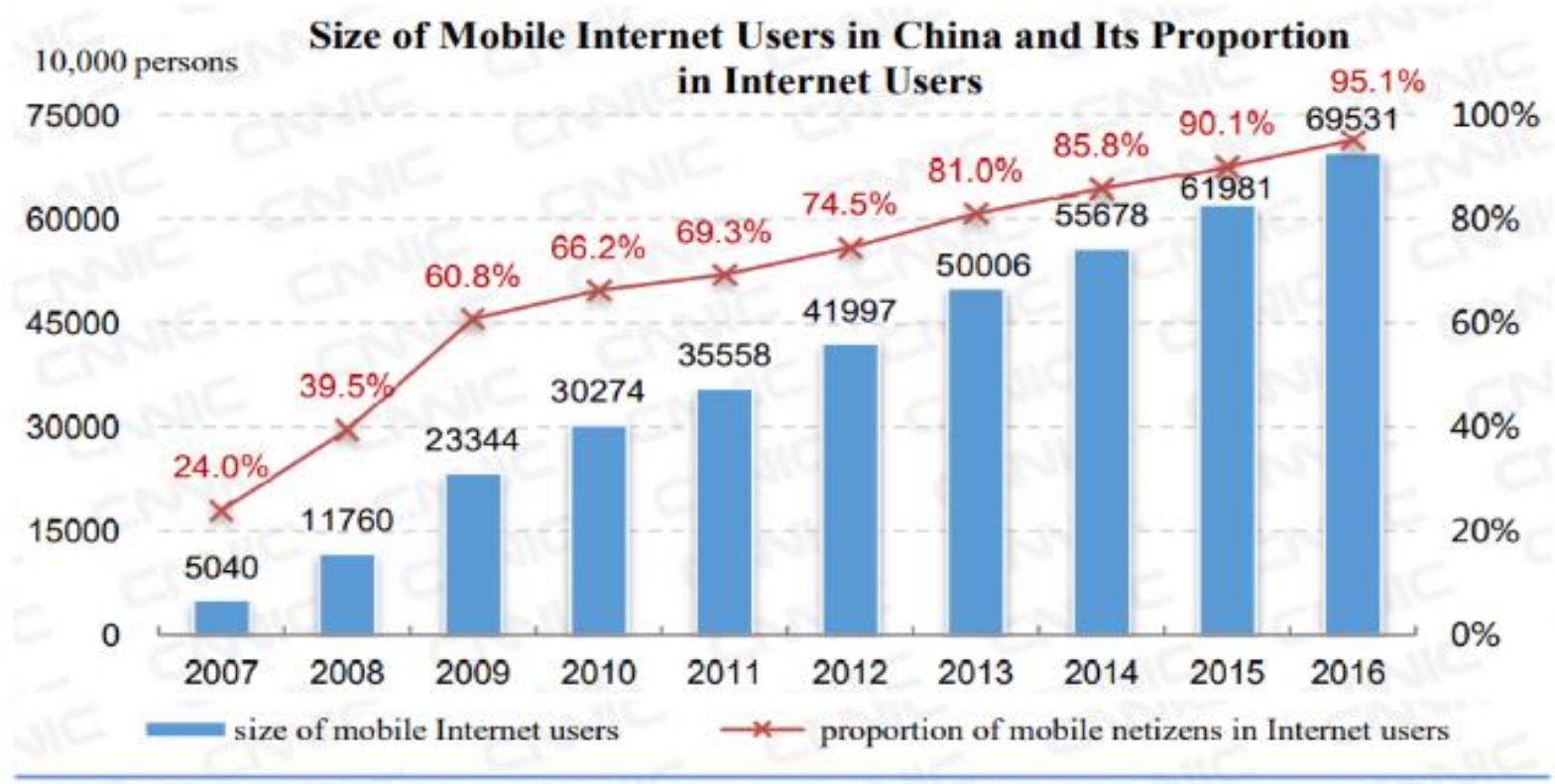

Source: $\mathrm{C}$ - Statistical Survey on Internet Development in China 2016.12

Figure 1: Size of Mobile Internet Users in China and Its Proportion of Internet Users (CNNIC 2017). 


\subsection{Chinese Censorship of Art and Social Media}

In the UK, in 2017, the Department for Digital, Culture, Media and Sport (DCMS) was created as one ministry that now covers the digital sectors, telecommunications, data protection, Internet safety, cyber skills, parts of the media and also creative industries. In China, there is greater separation. The digital world is placed under the Ministry of Industry and Information Technology (MIIT) and the Cyberspace Administration (linked to China's new cyber-security laws), whilst culture and the arts remain under the Chinese Ministry of Culture. These organisational differences may indicate different attitudes towards the digital world as part of a shared living culture.

President Xi's 2015 speech, Talks at the Forum on Literature and Art Work, emphasised the 'rejuvenation' or 'restoration' of Chinese culture, in reference to 'traditional' arts. His speech has been translated and truncated by ChinaFile (2014).

As of January 2018, China's ruling Communist Party will enshrine President Xi Jinping's political thought into the country's constitution; this includes Xi's positional thought on all the arts. Xi acknowledges that the trend of globalisation in the arts cannot be reversed, however, he asserts that, at least within China, it can be managed and controlled. Xi's critique of the trends in the arts encompasses broad criticism of 'art for art's sake', 'vulgarisation of culture', 'the fickleness of contemporary culture', and he called for contemporary arts in China to take up patriotism as a cause. The continuation and massive extension by President $\mathrm{Xi}$ of Deng Xiaoping's period of economic liberalisation from the late 1970s until 1997 retain concern and suspicion regarding the outcomes of a similar liberalisation in the arts.

The objection to a greater liberalisation of the arts and culture for those inside the party is that they see it not just leading to serious developments of the negative aspects of bourgeois liberalisation but a total overwhelming moral and social collapse. The protectionism and caution of China's ruling party stem from the historical outcomes of cultural 'slackness', which resulted in the Tiananmen Square protests. For the majority of China's ruling elites, the issue is not actually in any infection of western cultural hedonism. China has developed and translated western culture and made 'sufficient' commercial success in the production of a sanitised Chinese version of it. It incorporates images, music and movies that safely offer the frisson of a popular culture but within 'Chinese characteristics'. For China's government cultural censors, the concerns are often focused on the 50 million ethnic Chinese living outside China, many of whom speak Chinese, and are viewed as actively politically dissident and anti-China.

While political factors remain an issue, activity in the arts will always find a way to continue either by luck or by strategic management. The China Digital Art Association (DAC) is an example of a new modern Chinese arts organisation. It concerns the age of digitisation and breaks down barriers between art and technology. It has also made many moves regarding the integration of traditional art into digital art in China and exploration of the issue. Digital art is often linked to great demands in digital marketing but artist collectives, such as Digitalarti and the Chronus Art Center in Shanghai, are increasingly becoming examples of innovation in digital visual arts that are both uniquely Chinese and globally connected to work that combines art and technology (Ling, 2014). Time Out Beijing recently published an article that recommended five Chinese Internet artists and platforms (Feola 2017).

As part of the 2017 Chinese cybersecurity laws, companies are required to report the online activities of their employees. This arose from concerns of corporate activity on WeChat. It resulted in many citizens feeling the effects of tightening restrictions. Many artists such as Xu Wenkai, who uses the pseudonym Aaajiao reported that he was 'feeling nervous' to The Art Newspaper. Sixty accounts were initially forcibly closed in the following weeks, many of the visual artists. In addition to being monitored, social media users are also now completely denied online anonymity. This ended Aaajiao's career (Tsionki 2016).

However, artists and galleries saw negative effects, by having their accounts on WeChat closed and censored (Feola 2017). They see censorship as an attack on intellectual life that impoverishes many. Artistic culture often maintains that freedom is essential to create and therefore censorship anywhere must be seen as an inconvenience to be overcome. Ai Weiwei wrote an article in May 2017 in the New York Times entitled How Censorship Works. In it, he wrote:

'Life in China is saturated with pretence. People feign ignorance and speak in ambiguities. Everyone in China knows that a censorship system exists, but there is a very little discussion of why it exists.'

\section{HOW DOES DIGITAL CURATION INTERACT WITH WECHAT}

In China, WeChat and Sina Weibo are the largest social media platforms. At least 115 of the 130 nationally in China recognised first-class museums have registered on WeChat, and 103 have already registered on Weibo (Lei et al. 2018). 


\subsection{WeChat}

WeChat (微信; pinyin: Wēixìn; literally: 'micromessage') is a Chinese multi-purpose messaging and social media app developed by Tencent. It was first released in 2011 , and by 2018 it was one of the world's largest standalone mobile apps in terms of monthly(Brennan 2018) active users, with over 1 billion monthly active users (902 million daily active users). It has been called China's 'App for Everything' and a 'Super App' because of its wide range of functions and platforms (see Figure2).

It is important to understand how WeChat drives its over 1 billion monthly active users to use the app an average of $50+$ minutes, and 9-11 separate times per day. To put this in context, it is the same as the combined time users spend on a portfolio of Facebook apps, including Instagram, Facebook and Facebook messenger, on a daily basis.



Figure 2: WeChat App user interface

\subsection{Weibo}

Sina Weibo is a microblogging (Weibo) website. Launched by Sina Corporation on 14 August 2009, it is one of the most popular social media sites in China. As of the $4^{\text {th }}$ quarter of 2017, Sina Weibo has over 392 million monthly active users (Lei et al. 2018).
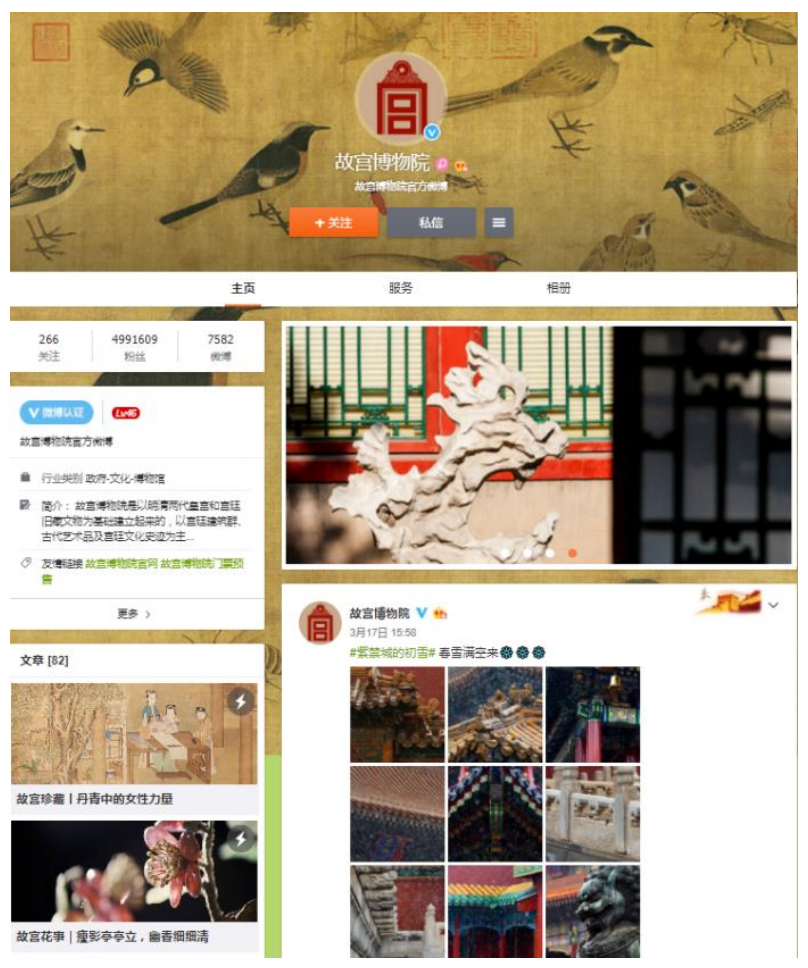

Figure 3: Forbidden City Official Weibo Account. The caption to go below figure.

The above image is a picture of the Forbidden City official account, including three major sections: tickets; cultural and creative; and publishing. They interact with tourists. The official account has $4,991,609$ followers and 7,582 Weibo, with a daily average of 500 comments and interactions on each Weibo. Tourists can also get discounts from the Weibo, with a link back to their website.

Digital curation involves maintaining, preserving and adding value to digital research data throughout its lifecycle. The definition of a digital curation rationale is maintaining and adding value to a trusted body of digital information for current and future generational use.

\subsection{Museums Using WeChat in the Dissemination of My Personal WeChat Blog}

I will use a case study of exhibitions as part of a WeChat blog strategy. From personal experience as a cultural events blogger, independent public reviews and online word-of-mouth recommendations remain influential. WeChat blogger reviews that are informative, knowledgeable, trusted and offer an informed opinion increase interest in exhibitions, collections and cultural institutions themselves. This form of communication engages with hard-to-reach groups and helps to increase inclusion in national cultural life.

As a freelance journalist, after I visit an exhibition, I review it on my WeChat blog. An example is a 
review of the Impressionists in London exhibition at Tate Britain.

\section{他画的是雾䨪|1870-1904法国流亡印象派大师的伦敦印象 \\ (Original) 2018-02-22 格格 Kings人文 \\ 我们画的只是印魚而已-一莫奈



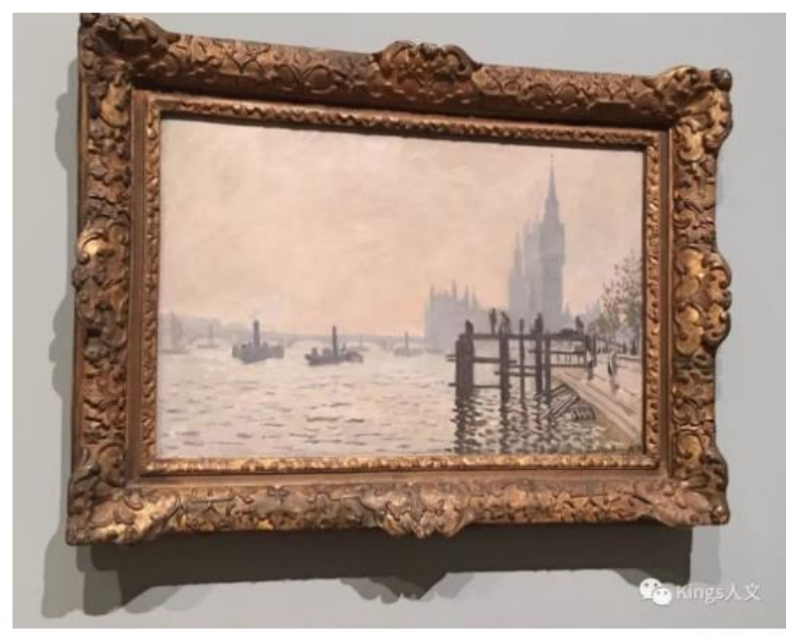

Cleude Yonet. 1871. The Thanes belon Testminster

Figure 4: My WeChat blog-King's 人文 (Humanities). The caption to go below figure

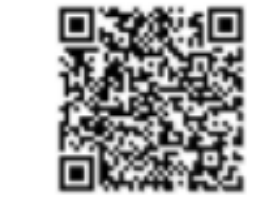

Scan QR Code via W eChat

to follow Official Acco unt

\section{$¥ 5.00$} 给小编格格买杯奶菜䏝?

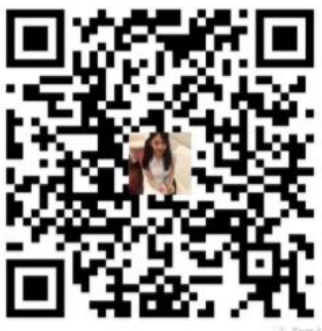

Figure 5: WeChat Pay Function. The caption to go below figure (if you enjoy the paper you could scan it)

After the reader reads the post, they can scan the code and pay money to the author if they wish. WeChat Pay is a very important function of WeChat and also shows admission.

\section{CHINA: SOFT POWER AND CULTURAL DIPLOMACY IN THE DIGITAL AGE}

The aim of exercising soft power is to create an image of a country and give it credit and status inside global networks. How do the arts and culture contribute to this and how can it be measured? The American political scientist Nye (2005) outlined in his book Soft Power: The Means to Success in World Politics that one of the three key elements of any nation's soft power is its culture. This includes the creation of digestible and translatable cultural heritage and historical narratives linked to notions of modernising progressive projects consumable for both the satisfaction of internal and external audiences. Narratives are also being created by futurologists that spin 'positives' either by ignoring or using rhetorical devices to overcome the conundrum best described through Kenneth Boulding's remark 'Anyone who believes in indefinite growth in anything physical, on a physically finite planet, is either mad or an economist.'

A great example of soft power is its ability to attract and co-opt rather than using any physical coercion (hard power). China's 'One Belt One Road Initiative' combines or fictionalises (depending on one's perspective) many elements of a created shared cultural connectivity regarding the history of the Silk Road, offering many former trading countries a mutual 'win-win' formula of Chinese economic expansionism. The question remains whether China has enough economic power to impose it as a coercive hard power. All the soft power is then simply half-heartedly absorbed and accepted as the consequences of this new economic reality.

The manufactured soft power image importantly has to incorporate modernising cultural elements in terms of advancing technologies, the media, digital assets, visual arts and film. This really began for China in the 2008 Beijing Olympics and the presentation of a youthful vibrancy in hyper-growth economies such as China is still essential to encourage old-fashioned trade, investment and tourism. The arts can be utilised in difficult contexts to create open and safe spaces for relationships and connections to develop. They must maintain traditional values whilst offering creative innovation that may only arrive through an avant-garde push and within China, the avant-garde is limited by having to act within political constraints.

This avant-garde requirement or imperative may be best understood through the famously controversial example of how the American CIA secretly funded abstract expressionism during the Cold War, as described in the books of Stonor Saunders (2013) and Guilbaut (1985), amongst others.

The seemingly contradictory mental image of China today can be described by a great strength and stability arising from 5,000 years of civilisation while also having weakness in terms of its censorship and protectionism against any form of iconoclasm, whether it is in the form of a political joke, a meme, or Ai Weiwei.

In 2017, King's College London published the report The Art of Soft Power, describing the agenda of soft power as: 


\begin{abstract}
Means bringing together diplomacy, cultural relations and national interest in a way which turns away from relying solely on military intervention and humanitarian aid and instead provides a more holistic way to promote our values and help others.
\end{abstract}

There are then mutual benefits on both sides in soft power, with many protocols, initiatives and great efforts in translation being involved. Any evaluation of what is effective needs to assess the influence by evaluating whether people are saying, doing or feeling things differently because of soft power initiatives. Culture is a convoluted affair for governments as the politics and business involved in it and the measurements and data regarding the impact of cultural works are extremely complex.

For artists themselves, it may well be that while recognising the wider context that they engage with, this measurement of their contribution to soft power is the least important to them. The works themselves may also be less important to artists, who were involved in intercultural understanding and sharing the artistic process itself by creating networks and new insights may be the most important result for them.

According to Stuart Hall's reception theory (1980), none of this is really a passive process, but rather an active one. The processes of soft and hard power can be crudely categorised and measured by degrees of propaganda effectiveness, promotion, and economic outcomes in creating a better image of authority. Trust, cohesion and understanding arise in the exchange and adoption of ideas and information, and observing a culture and its artefacts closely can lead to new ways of working that become translatable and can then be transformed into changed social praxes. Cross-cultural understanding in the arts for both viewers and in shared artistic practice is complex, convoluted and characterised by aesthetic misunderstanding, a range of emotions and questioning subjectivity. We, therefore, need to leave room for non-absolutes, the unforeseeable, and the inscrutable itself and recognise that the arts always pose questions but sometimes the answers are different to the ones we expect.

So, what role do the arts have a soft power in the digital age? Does this role require the acceptance of the weaponisation of the arts in contemporary politics? The concept of cultural diplomacy first reached a level of importance during the Cold War when American creations such as jazz were seen as the embodiment of an anti-ideology artform. With the development of institutions such as the British Council and the China Cultural Centre, culture and the arts became a central political tool with artefacts being used in processes as hostages and tools of exchange. While cultural diplomacy and exchanges grow between China and the west, it is within a set of safe ideological visitor exchange programmes, 'a Matisse for a Ming' so to speak.

Impressionist art exhibitions are extremely popular in China and are discussed on social media platforms. This is often the first experience of seeing western artistic traditions for many ordinary Chinese citizens. In the UK, museums and academic Sinologists also have greater access to Chinese artefacts. Sensitivities arise, for example, with the tradition of propaganda posters in China, which were often seen before the Cultural Revolution when Chinese history was fully revised (Feola 2017). The public amnesia of certain historical moments is part of the greater form of censorship both in terms of texts and images. When explaining the fame of $\mathrm{Ai}$ Weiwei as an artist in the west to an ordinary Chinese person, they may still see him as an antiChinese propagandist paid by the west. Within WeChat, the absence of controversial political debate affects the arts and this is not just due to the censorship from the 50 Cent Army, but mainly through self-censorship of users themselves as a reactive secondary nature.

\section{CONCLUSION}

As China grows economically, it also wants to be better understood, specifically in terms of how its ancient history influences its psychology and attitudes today in a uniquely non-problematic way for the Chinese. China has no tradition of democracy, rather it has various models of group harmonisation strongly arising from Confucianism. President Xi's slogan of 'Socialism with Chinese Characteristics' is descriptive of a China claiming a uniquely Chinese way of embracing global capitalism. For Chinese arts and culture as elements of soft power, they are part of global or nationalistic contemporary power plays but are also concerned with creating a real understanding of their contribution to 5,000 years of human civilisation that they feel has been forgotten, while the focus has been on the west.

It is too early to write any critique of China as a global influencer in terms of its growth in its digital platforms and if Sino Weibo becomes larger than Google, the outcome remains unclear. The question may now be how can a society like China, which has invested in a massive complex regulated and censored Chinese intranet to both satisfy and pacify its society, with all these controls and restrictions, develop a global Internet that would not apply the same dynamics? Is this indeed a Chinese ambition?

China's previous failures in global digital markets such as Alibaba were due to a suspicion of Chinese tech companies and issues of data storage. This 
issue of trust is something they need to address together with western tech companies. The key word in this context is 'trust'. The mistrust socially constructed or otherwise, between China and the west is obvious if one follows popular media propaganda; there have been anti-Chinese or antiwestern sentiments on both sides. From notions of the Yellow Peril to claims of corrupting western moral decadence, this rhetoric has been useful in creating deliberate misunderstanding in an ideological war that requires each group to see the other as alien in culture and temperament. Today, that lack of trust has, to some degree, become outdated in its usefulness and it cannot now get in the way of business. Common misconceptions about contemporary society and history are being corrected slowly. Art and culture are at the forefront to lead the way to a better understanding of the 'other'. Artistic exchange develops the possibility of a new accord, a rapport, a better word, also in French, maybe retrouvailles: 'The happiness of meeting again after a long time'. That meeting will occur in the shared language of the artists themselves and eventually in an unfettered truly free globalised Internet.

\section{REFERENCE}

Benjamin, W. (1935) The Work of Art in the Age of Mechanical Reproduction. Journal of Philosophy of Education, 41(3), pp.363-380.

Bowen, J. P. and Giannini, T. (2014). Digitalism: The new realism. In S. Dunn, J. P. Bowen, \& K. Ng (eds.). EVA London 2014 Conference Proceedings, Electronic Workshops in Computing (eWiC), British Computer Society, pp.324-331. DOI:

10.14236/ewic/eva2014.38

Brennan, M. (2018) Wechat new year data report 2018. [online] Available at: http://theunitldn.com [Accessed 1 Mar. 2018].

Eilean, H. G. (2007). Museum revolutions: how museums and change and are changed / edited by Simon J. Knell, Suzanne MacLeod and Sheila Watson, 367-377. Published by Routledge, 2007.

Guilbaut, S. (1895) How New York stole the idea of modern art. Chicago [u.a.]: University of Chicago Press.

Hertz, R. (1993) Theories of contemporary art. Pearson; 2 editions.

Nye, J. (2005) Soft Power: The Means to Success in World Politics. New York: Public Affairs.

Saunders, F. (2013) The cultural Cold War. New York: The New Press.

Business Insider (n.d.) [online] Available at: http://uk.businessinsider.com/instagram-galleryunit-london-1-2015 [Accessed 11 Jan. 2018].
CNNIC (2017) Statistical Report on Internet Development in China, China Internet Network Information Centre. China Internet network information centre. [online] Available at: https://cnnic.com.cn/IDR/ReportDownloads/201706 IP020170608523740585924.pdf [Accessed 19 Mar. 2018].

Digitalarti. (2015) Shanghai New Media Artists and Galeries - Digitalarti. [online] Available at: https://www.digitalarti.com/shanghai-new-mediaartists-and-galeries/ [Accessed 20 Mar. 2018].

Feola, J. (2017) 5 Chinese Internet artists and platforms to check out. [online] Timeoutbeijing.com. Available at:

http://www.timeoutbeijing.com/features/Art/158150/ 5-Chinese-Internet-artists-and-platforms-to-checkout.html [Accessed 20 Mar. 2018].

Fireworksnewyears.com (2018) Xi Jinping Talks at The Beijing Forum on Literature and Art China - Xi Jinping's Talks at the Beijing Forum on Literature and Art " China .... [online] Available at:

https://fireworksnewyears.com/info/xi-jinpings-talksat-the-beijing-forum-on-literature-and-art-china [Accessed 20 Mar. 2018].

Gibson, L. (2012) Museums and Participation (Who goes. And who doesn't?). Understanding Everyday Participation. [online] Available at: http://www.everydayparticipation.org [Accessed 28 Mar. 2018].

Gibson, L. and Miles, A. (2014), 'Understanding Everyday Participation- Articulating Cultural Value', Development Project, AHRC, Universities of Manchester and Leicester. [online] Available at: http://www.everydayparticipation.org/wpcontent/uploads/2014/05/UEP Briefing Cheetham Broughton.pdf [Accessed 11 Feb. 2018].

Lei, K., Liu, Y., Zhong, S., Liu, Y., Xu, K., Shen, Y. and Yang, M. (2018) Understanding User Behavior in Sina Weibo Online Social Network: A Community Approach. 6:13302-13316. DOI: 10.1109/ACCESS.2018.2808158

Ling, G. (2014) Chronus Art Center: R\&D First, China's Own ZKM Next? [online] Chronusartcenter.org. Available at:

http://www.randian-online.com/np feature/chronusart-center/ [Accessed 20 Mar. 2018].

Tsionki. (2016) Remnants of an Electronic Past": Chinese new media artist aaajiao - in conversation. [online] Chronusartcenter.org. Available at: http://artradarjournal.com/2016/09/16/remnants-ofan-electronic-past-chinese-new-media-artistaaajiao-in-conversation/ [Accessed 20 Mar. 2018].

Unite London. (n.d.) [online] Available at: http://theunitldn.com [Accessed 20 Mar. 2018]. 